\section{Removing Potassium-deficient Leaves Accelerates Rate of Decline in Phoenix roebelenii O'Brien}

\author{
Timothy K. Broschat \\ University of Florida, Fort Lauderdale Research and Education Center, 3205 \\ College Avenue, Fort Lauderdale, FL 33314
}

Additional index words. Palmae

Potassium deficiency is a widespread and often serious disorder on many species of palms throughout the world (Chase and Broschat, 1991). Early symptoms usually include translucent yellow, orange, or necrotic spotting of the oldest leaves. This is usually accompanied by marginal necrosis on leaves or leaflets that eventually gives the oldest leaves a gray frizzled appearance (Broschat, 1990; Chase and Broschat, 1991). Potassium is mobile within plants, and deficiency symptoms are most severe on the oldest leaves, becoming less severe on younger leaves (Mengel and Kirkby, 1982). As the K deficiency becomes more severe, the symptoms will affect progressively younger palm leaves until no symptom-free leaves remain. At this point, if not treated, new leaves will emerge chlorotic. They will be reduced in size and have extensive necrosis. Death of the palm's only shoot meristem often follows (Broschat, 1990).

Leaves normally remain on a healthy palm for 2 or more years, depending on the species, and each palm will retain a species-specific number of leaves (Tomlinson, 1990). Mildly $\mathrm{K}$-deficient leaves are typically removed during landscape maintenance because they are visibly discolored; severely deficient leaves appear dead except for the rachis and adjacent areas of the leaflets. Under conditions of $\mathrm{K}$ deficiency, $\mathrm{K}$ from the oldest leaves is mobilized for use by the newly expanding leaves. Premature removal of the oldest K-deficient leaves may remove a $\mathrm{K}$ source needed for plant growth. Potassium required for continued growth may be mobilized from the oldest remaining leaves that previously may have been symptom-free. As these leaves become symptomatic and are subsequently removed, still younger leaves may be used as a source of $\mathrm{K}$ by the meristem. Thus, removal of $\mathrm{K}$ deficient leaves may accelerate the rate of

\footnotetext{
Received for publication 30 Aug. 1993. Accepted for publication 26 Jan. 1994. Florida Agricultural Expt. Station Journal Series no. R-03362. The cost of publishing this paper was defrayed in part by the payment of page charges. Under postal regulations, this paper therefore must be hereby marked advertisement solely to indicate this fact.
}

decline from $\mathrm{K}$ deficiency in palms. This study tests this hypothesis on pygmy date palms, a species highly prone to $\mathrm{K}$ deficiency and one that matures at a small enough size to be grown easily in containers.

Mature pygmy date palms with gray trunks $\geq 30 \mathrm{~cm}$ long were transplanted from 24-liter containers into 38-liter polypropylene containers using a 5 pine bark $: 4$ sedge peat : 1 sand medium amended with $880 \mathrm{~g}$ Micromax and $4.9 \mathrm{~kg}$ dolomite $/ \mathrm{m}^{3}$. Mild $\mathrm{K}$ deficiency occurred on palms fertilized with $200 \mathrm{~g}$ of Osmocote $17 \mathrm{~N}-3 \mathrm{P}-10 \mathrm{~K}$ per container every 6 months, and moderate $\mathrm{K}$ deficiency was induced by fertilizing with $160 \mathrm{~g}$ of Osmocote $17 \mathrm{~N}-3 \mathrm{P}-10 \mathrm{~K}$ and $40 \mathrm{~g}$ of Osmocote $40 \mathrm{~N}-0 \mathrm{P}-$ OK plus $20 \mathrm{~g}$ of $\mathrm{MgSO}_{4} \cdot \mathrm{H}_{2} \mathrm{O}$ per container. Within each fertilizer treatment, 10 replicate palms had only dead leaves removed every 3 months, and 10 had dead and K-deficient leaves removed on the same time interval. A leaf was considered deficient if more than three leaflets had tips with $1 \mathrm{~cm}$ or more of orange discoloration.

Palms were grown under full sun (maximum PPF $\left.=2100 \mu \mathrm{mol} \cdot \mathrm{m}^{-2} \cdot \mathrm{s}^{-1}\right)$ and received water from rainfall and overhead irrigation. After 18 months, the number of dead, deficient, and green leaves per tree were counted, and leaf samples consisting of the central 10 leaflets from the most recently matured leaf and the second oldest living leaf on each tree were collected for nutrient analysis. Leaf samples were dried, ground, and digested using a modified sulfuric acid and hydrogen peroxide procedure (Allen, 1974), with K concentrations determined by atomic absorption

Table 1. Effects of periodic trimming of K-deficient leaves over 18 months on the canopy structure of mildly and moderately deficient pygmy date palms.

\begin{tabular}{lccc}
\hline \hline Palm K status and & \multicolumn{3}{c}{ No. leaves } \\
\cline { 2 - 4 } leaves removed & Green & Deficient & Dead \\
\hline Mildly deficient & & & \\
Dead and deficient & 23.1 & 7.0 & 1.7 \\
Dead leaves & 29.2 & 12.0 & 10.5 \\
Significance (P) & 0.02 & NS & 0.0001 \\
Moderately deficient & & & \\
Dead and deficient & 18.4 & 9.1 & 0.2 \\
Dead leaves & 24.7 & 27.7 & 10.3 \\
Significance (P) & 0.02 & 0.001 & 0.0002 \\
\hline "Nonsignificant. & & &
\end{tabular}

spectrophotometry (Perkin-Elmer Corp., Norwalk, Corm.). We tested data by analysis of variance.

Mildly and moderately K-deficient palms that had deficient and dead leaves trimmed had significantly fewer green nonsymptomatic leaves than those having only dead leaves removed (Table 1). These results support the hypothesis that removal of K-deficient leaves results in reduced canopy size and an accelerated rate of decline from $\mathrm{K}$ deficiency. In addition, significantly fewer dead and deficient leaves remained on the moderately deficient plants if both dead and deficient leaves were removed compared to plants with only the dead leaves removed (Table 1).

For mildly deficient palms, the number of green and dead leaves was reduced by removing deficient and dead leaves compared to removal of only dead leaves. For both trimming treatments, the number of green leaves retained by moderately deficient palms was less than for the mildly deficient palms of the same leaf removal treatment $(\mathrm{P} \leq 0.05)$, suggesting that the number of green leaves retained also may be related to the amount of $\mathrm{K}$ in the soil available to the palm.

When old and recently matured leaves were analyzed for leaf $\mathrm{K}$ concentrations, no significant differences existed among any treatments (data not shown). It appears that as long as older leaves are available to supplement $\mathrm{K}$ taken up from the soil, the $\mathrm{K}$ content of recently matured leaves will remain relatively constant until all leaves are deficient. Similar results were reported for K-deficient African oil palms (Elaeis guineensis Jacq.) (Hartley, 1988). Assuming that $\mathrm{K}$ is mobilized at a constant rate from oldest leaves under conditions of similar K deficiency, the K concentrations in the second oldest leaves also should be equivalent, regardless of the number of green leaves above it in the canopy.

In conclusion, canopy size (green leaves and total living leaves) was reduced after 18 months of $\mathrm{K}$ deficiency in pygmy date palms when deficient leaves were periodically removed, compared to palms from which only dead leaves were removed. This finding shows that the removal of deficient leaves takes away a significant $\mathrm{K}$ source for the growing meristem and accelerates the rate of decline from K deficiency.

\section{Literature Cited}

Allen, S.E. (ed.). 1974. Chemical analysis of ecological materials. Blackwell Scientific Publ., Oxford, England.

Broschat, T.K. 1990. Potassium deficiency of palms in south Florida. Principes 34(3): 151-155.

Chase, A.R. and T.K. Broschat (eds.). 1991. Diseases and disorders of ornamental palms. Amer. Phytopathol. Soc. Press, St. Paul, Minn.

Hartley, C.W.S. 1988. The oil palm. Longman Science \& Technology, Essex, England.

Mengel, K. and E.A. Kirkby. 1982. Principles of plant nutrition. 3rd ed. Intl. Potash Inst., Berne, Switzerland.

Tomlinson, P.B. 1990. The structural biology of palms. Clarendon Press, Oxford, England. 